\title{
PUBLIC GOOD OR COMMERCIAL OPPORTUNITY: CASE STUDIES IN REMOTE SENSING COMMERCIALIZATION
}

\author{
Shaida Johnston, NASA, Goddard Space Flight Center, Greenbelt, MD \\ Joseph Cordes, Professor of Economics, George Washington University, Washington, DC
}

\begin{abstract}
The U.S. Government is once again attempting to commercialize the Landsat program and is asking the private sector to develop a next generation mid-resolution remote sensing system that will provide continuity with the thirty-year data archive of Landsat data. Much of the case for commercializing the Landsat program rests on the apparently successful commercialization of high-resolution remote sensing activities coupled with the belief that conditions have changed since the failed attempt to commercialize Landsat in the 1980s. This paper analyzes the economic, political and technical conditions that prevailed in the 1980s as well as conditions that might account for the apparent success of the emerging high-resolution remote sensing industry today. Lessons are gleaned for the future of the Landsat program.
\end{abstract}

\section{INTRODUCTION}

In the early 1980 s U.S. policy makers were discussing commercializing Landsat, a satellite system that had at that point been generating global monitoring data continuously for ten years". The general discussion and rationale revolved around a constrained national budget and a trend toward commercializing government functions in an effort to reduce direct government costs. The development of a commercial market for satellite remote sensing data was expected to take at least a decade. Independent studies of mechanisms to transfer Landsat to the private sector concluded that no viable options existed without substantial government subsidy. ${ }^{1}$ Nonetheless, a proposal to commercialize land and weather satellites was submitted to Congress. The result was two public laws enacted in 1984. One, P.L. 98-166, which prohibits the U.S. government from privatizing the operational weather satellites and the other, P.L. 98-365, which established a process for commercializing Landsat and licensing private land remote sensing satellites.

Thus began the experiment to commercialize Landsat. Earth Observing Satellite Corporation (EOSAT) was selected to operate the Landsat system (Landsats 4 \& 5) under a 10-year contract and to build two new spacecraft (Landsats $6 \& 7$ ). With this contract came the exclusive rights to market Landsat data ${ }^{\dagger}$ and collect foreign ground station user fees. The U.S. government was to provide $\$ 250 \mathrm{M}$ for spacecraft development over five years. The subsequent eight years were rife with funding uncertainties, contract renegotiations, and a lack of coherent government policy for the Landsat program. The experiment culminated when Congress passed the 1992 Land Remote Sensing Policy Act, repealing the 1984 Land Remote Sensing Commercialization Act (P.L. 98-365) and acknowledging that the commercialization of Landsat had not succeeded.

Today, multiple satellites are available nationally and internationally observing the Earth. Space Imaging Corp. launched IKONOS, the first commercial high-resolution $(<1 \text { meter })^{\ddagger}$ satellite in the U.S. in 1999 and DigitalGlobe launched the second with Quick Bird in 2001. In addition, Canada, France, India, Israel, Russia and Japan have systems from which one can buy satellite-based, remotely sensed data. The U.S. commercial systems listed above provide high spatial resolutions by trading off swath width or geographic coverage in their designs ${ }^{\S}$, a necessary compromise for space-based sensors. Limited sensor swath widths preclude sensing the entire Earth's surface, or even the entire land mass, comprehensively or repeatedly - a capability required for large-scale natural resource monitoring or global climate change studies. Figure 1 provides a graphical comparison of the range of swath widths and spatial resolutions available from some sensors today.

\footnotetext{
- The first Landsat, originally called Earth Resources Technology Satellite-1 (ERTS-1), was launched in 1972.

${ }^{\dagger}$ EOSAT had exclusive rights to data collected prior to the date of the contract (9/85) until its expiration date (7/94). EOSAT today is Space Imaging Corp.

₹ Spatial resolution, also sometimes designated as Ground Sample Distance (GSD) is the size of the smallest object on the ground that can be distinguished by the sensor (the size of one pixel).

"Space Imaging's IKONOS and DigitalGlobe's Quick Bird satellites provide a swath width of $11 \mathrm{~km}$ and $16.5 \mathrm{~km}$ respectively which determines the size of a 'scene'.
} 


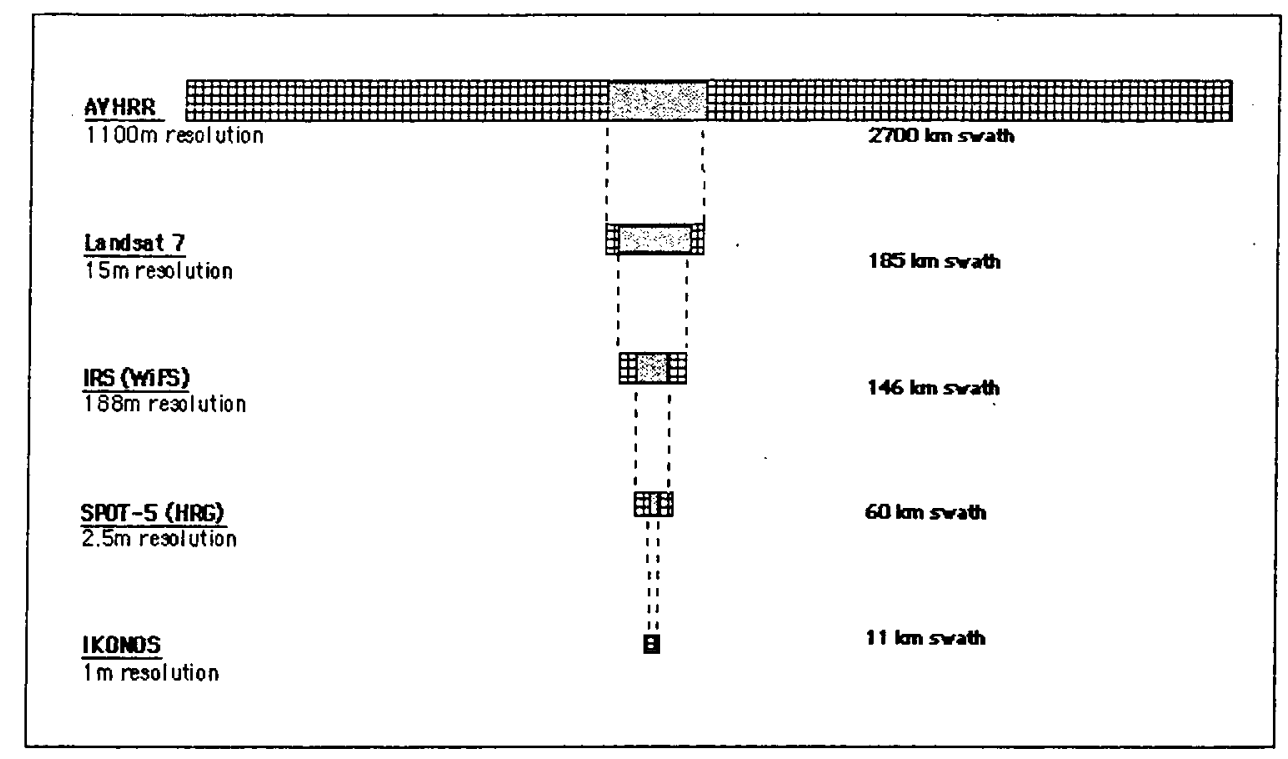

Figure 1 - Swath Width Comparison of Selected Sensors

The same commercial systems are also designed with the flexibility to point off-nadir to acquire scenes requested by customers in the most timely fashion. This is an optimum design for maximizing profitability, but it trades off characteristics such as systematic global coverage and repeatable viewing geometry, which are typical of broad coverage systems such as Landsat and the Advanced Very High Resolution Radiometer (AVHRR). We are still not able to have it all in one system. As a result, it is important to make a distinction between these two types of Earth remote sensing satellite systems. Table 1 distinguishes the characteristics of high-resolution, limited coverage systems (LCS) from those of broad spatial and spectral coverage systems (BCS). The distinction is made now in order to later clarify the difference in user base and market demand of the two types of systems.

Table 1 - Characteristics by System Type

\begin{tabular}{|l|l|}
\hline \multicolumn{1}{|c|}{ Broad Coverage Systems (BCS) } & Limited Coverage Systems (LCS) \\
\hline Large Swath Width $(100-3000 \mathrm{~km})$ & Small Swath Width $(<100 \mathrm{~km})$ \\
\hline Medium to Low Spatial Resolution & High Spatial Resolution \\
\hline Multiple Spectral Bands & Limited Spectral Bands $(1-2)$ \\
\hline On-Board Calibration & Relative Calibration \\
\hline Synoptic Geographic Coverage & Pointable/Selective Tasking \\
\hline
\end{tabular}

Much has changed in the remote sensing world since the 1980's and the Landsat program is to be commercialized once again, though this time through the program implementation process" rather than congressional legislation. This paper will look at the conditions that existed in 1984 along with what has changed in the last eighteen years to determine whether there are lessons to be learned for Landsat's future. The paper is organized to identify the technical, legal, policy and economic conditions that existed in the two time frames, 1984 and 2001.

\section{State of Technology}

\section{CONDITIONS}

Landsat 4 was launched in 1982 and represented the best Earth remote sensing satellite capability in the civil sector in 1984. The new Thematic Mapper (TM) sensor, with its seven spectral bands, provided additional capability and spatial resolution over the Multi-Spectral Scanner (MSS). The two sensors were flown on the same spacecraft (Landsat 4) to provide continuity of data, in addition to continuity of the

\footnotetext{
"* The Landsat program management is shared by the National Aeronautics and Space Administration (NASA) and the U.S. Geological Survey (USGS) within the Department of the Interior (DOI).
} 
mission. No on-board tape storage was used for Landsat 4 image data but data were being transmitted at the higher rate of $85 \mathrm{Mbps}$ rather than the previous $15 \mathrm{Mbps}$ for Landsats 1-3. NASA's new Tracking and Data Relay Satellite System (TDRSS) allowed data to be relayed from Landsat 4 to the ground from most areas of the globe. In addition, a network of international ground stations existed to receive Landsat data directly from the spacecraft when within station field of view.

AVHRR, designed to measure sea surface temperature and provide information on ice, snow and cloud formations, had been flying on (National Oceanographic and Atmospheric Administration) NOAA's polarorbiting weather satellites since 1978, providing daily coverage of the Earth with its swath of about 2700 $\mathrm{km}$. In 1984, the AVHRR had five spectral bands, a spatial resolution of $1.1 \mathrm{~km}$, and an already significant archive of continuous data. NASA's Nimbus-7 satellite carried meteorological sensors measuring atmospheric phenomena and the experimental Coastal Zone Color Scanner (CZCS), which provided the first ocean color measurements. Multi-spectral imaging capabilities and applications were expanding and new communications technologies were increasing data capture and transmission rates.

\section{Legal Framework}

The primary body of international law existing in 1984 that governed remote sensing satellites was the United Nations $(U N)$ Outer Space Treaty ${ }^{2}$. The UN Outer Space Treaty designates space and celestial bodies as non-sovereign territory, to be used strictly for peaceful purposes and calls for registration of manmade space objects. In addition, the UN Principles Relating to Remote Sensing of the Earth from Space ${ }^{3}$ were being drafted and negotiated within the international community. Principle XII, known as the principle of 'non-discriminatory access' turned out to be a fundamental piece of the commercialization conditions. The principle manifested itself within the 1984 Land Remote Sensing Commercialization Act by requiring private remote sensing operators to make data available to all potential users on the same terms, seriously hindering a private operator from determining their own fate and profits. ${ }^{4}$

\section{Policy Framework}

The Landsat program had initially been developed and operated by NASA. In 1979, President Carter transferred Landsat operations to NOAA ${ }^{\dagger \dagger}$. NOAA, as evidenced by its name, is an organization devoted to studying the oceans and atmosphere, awkwardly still located within the Department of Commerce (DOC). A land remote sensing system was not particularly of interest to the organization and since discussions of commercialization of Landsat had already begun, Landsat did not receive high priority within NOAA. In addition, NOAA as an organization was contending with much uncertainty. Between 1978 and 1985, at least three different proposals were advanced to move NOAA out of the DOC. President Carter recommended that NOAA be transferred to a Department of Natural Resources. President Reagan, in his first term, recommended that NOAA be made an independent agency as part of a reorganization of the DOC. In President Reagan's second term, a presidential commission recommended that NOAA be made part of a new Department of Science.

At the time of the Landsat program transfer to NOAA, President Carter also supported the long-term operation of Landsat with a gradual move toward privatization, acknowledging that it may take up to ten years to develop the market for such data. With the change of administration in 1981, President Reagan rejected President Carter's commitment to an operational program and the gradual transition to the private sector. Pressures to reduce government spending and shift operational costs to the private sector led the commercialization discussions. As a result, the pace was accelerated for Landsat's privatization. Studies were requested of DOC in 1981. Study results in 1983 concluded that no options existed for commercialization of Landsat without substantial government subsidy. Yet, swift implementation of the Land Remote Sensing Commercialization Act followed.

During this same period, U.S. weather satellites were being defined as essential public goods that must be provided by the government. The U.S. was moving in a direction of two separate operational systems for remote sensing of the Earth; one for land, to be transferred to the private sector; the second for the atmosphere, to be operated by the federal government. The 1984 legislation was silent on the subject of ocean remote sensing.

\footnotetext{
${ }^{\dagger \dagger}$ Presidential Directive NSC-54 transferred Landsat operations from NASA to NOAA, recommended development of a long-term operational system and four additional satellites beyond Landsat 3 , and recommended transition to private sector operation of Landsat.
} 


\section{Economic Framework}

In 1984, U.S. had a monopoly on land remote sensing with Landsat. The market pricing for commercial Landsat data, subsequent to the Land Remote Sensing Commercialization Act, reflected that monopoly ${ }^{\ddagger \ddagger}$. The barriers to market entry were, and continue to be, significant due to high development costs and long build times of satellite systems and the high risks involved in launching and operating such technology. Yet, even with market pricing well above marginal costs, recovery of start-up costs was not viable. The best that could be expected was that revenues of data sales would cover the fixed costs of operations. Government subsidy was required for developing the follow-on satellites and sensors for Landsat. Few private operators were interested in competing with a federally funded monopoly.

The assumptions necessary to figure the cost recovery for operations were based on optimistic demand projections and high market growth expectations. The demand elasticity for Landsat data had not been accurately determined at the time. The consequences of a nearly 600 percent increase in price was not known, though there were indications that demand would fall. In 1981, prices for MSS data increased more than 300 percent, to $\$ 650$ per scene $e^{\S \S}$, which resulted in a significant drop in the number of scenes purchased $^{5}$. The market pricing of Landsat data significantly inhibited users from using them and expanding their potential applications. Researchers chose to use the lower resolution, no cost, AVHRR data for global studies. In 1986, France's Systeme Pour l'Observation de la Terre (SPOT) was launched, which provided land remote sensing data with better spatial resolution than Landsat, at less cost to data purchasers. The U.S. monopoly was broken. Then in 1988, India launched the Indian Remote Sensing (IRS-1A) system and the competition expanded. The customer base for Landsat data did not grow as expected and the federal government remained the largest customer for Landsat data, with no individual agency willing to commit sufficient funds to continue its operations ${ }^{6}$.

By 1992, significant pressure had built up to return the Landsat systems to government operations and Congress passed the Land Remote Sensing Policy Act of 1992 (PL102-555), repealing the 1984 Land Remote Sensing Commercialization Act and returning the Landsat program to the federal government. Many analyses have been done assessing what factors affected this change in policy? ${ }^{7}$ Most consider the lack of stable government policy and the overly optimistic projections for market demand, large factors in the failure to commercialize Landsat. In addition, the open access requirement and competition with a federally funded monopoly kept private companies from entering the market. As a result, no commercial remote sensing licenses were requested between 1984 and 1992. Other forces were also at play. Landsat and SPOT data proved highly valuable during the 1990-1991 Persian Gulf War, having the distinct advantage of not being classified, thus shareable among allies.. The global change research community became active and vocal proponents of Landsat's public good value. And the European remote sensing effort continued to provide considerable competition for United States ${ }^{* * *}$. All of the above were strong motivators to move the Landsat program within the control of the federal government once again and revisit the policies in place for the expansion of the industry.

\section{State of Technology}

\section{CONDITIONS}

In 2001, dozens of civil, commercial, and international Earth remote sensing satellites generate data for users. Commercial satellite systems today provide high spatial resolutions of better than one meter. Satellite technology has advanced providing smaller and lighter spacecraft platforms for sensors and higher bandwidth communications allow greater volumes of data to be transmitted from spacecraft to the ground. Solid state on-board storage and processing, and data compression, allow data to be captured anywhere within an orbit and forwarded to the ground when within line of site of a ground station.

There has been a proliferation of Synthetic Aperture Radar (SAR) systems that are able to provide Earth observations that are not hindered by clouds or strictly daytime viewing. Stereoscopic and interferometric capabilities, from pointable and SAR systems respectively, have increased the number and accuracy of digital terrain models that have facilitated the growth of topographic and 3-dimensional

\footnotetext{
$\$$ The cost of Landsat data increased from $\$ 650 /$ scene to $\$ 4400 /$ scene.

$\$$ Office of Management and Budget (OMB) directed that system operating cost would be recovered by data sales, which meant that data prices would have to increase.

"** European Space Agency's (ESA) successful operation of the European Remote Sensing -1 (ERS-1) radar satellite and construction of ERS-2, as well as France's development of the Helios military reconnaissance satellite and SPOT2 demonstrated that Europe intended to continue investing in remote sensing technology.
} 
applications. In addition, ground point ties can be generated using the accuracy and ease of the Global Positioning System (GPS). These features facilitate integration of satellite remote sensing data into Geographic Information Systems (GIS) which have become essential tools for business and government planning. In addition to the dozens of satellite systems providing Earth observing data, there are many more 'value-added' data providers that market data products. A particular satellite sensor's data is marketed by multiple vendors, facilitating data access by users and providing an expanding set of product choices. Data processing and product generation from raw satellite data, are still difficult to master, requiring skills and tools not available to many customers today. Handling and processing satellite data to extract user unique information are not simple desktop procedures as yet and value-added vendors provide these essential services.

Though satellite launches have become somewhat routine and the technology is not much changed, technical risks of launch are still high. Six commercial remote sensing satellites have been lost due to launch failures ${ }^{t \dagger \dagger}$.

\section{Legal Framework}

The UN Remote Sensing Principles were finalized and adopted in 1987 as a resolution by the General Assembly. To date they have not reached treaty status but are considered customary international law?. The UN Remote Sensing Principles support remote sensing systems as public goods in both the ideological and economic senses of the term. The data are to be shared as openly as possible, on a non-discriminatory basis and for a reasonable cost. Unfortunately, this concept is in direct conflict with the interests of a commercial, profit making industry. Much of the commercial value of Earth remote sensing data is in exclusivity and timeliness to particular customers.

The 1992 Land Remote Sensing Policy Act strengthened the language and clarified the rules for NOAA to license commercial remote sensing systems that had originally been in the 1984 Land Remote Sensing Commercialization Act. The principle of non-discriminatory access was manifested in the act with language reflecting a requirement to make data available to the governments of the sensed states rather than to all potential users on the same terms. This allowed private companies to build a customer base of their own choosing, while still acknowledging the interests of foreign nations in preserving non-discriminatory distribution. As a result, the first commercial remote sensing license was issued in January 1993 and others quickly followed. Between 1993 and 2001, DOC granted seventeen licenses for operating commercial remote sensing satellites.

In addition, OMB issued a circular in February 1996 which impacts the pricing of remote sensing data distributed by the U.S. government. OMB Circular A-130 states that government agencies shall "set user charges for information dissemination products at a level sufficient to recover the cost of dissemination but no higher." Excluded are "costs associated with original collection and processing". Although OMB circulars do not in themselves have the force of law, this particular one is based on Paperwork Reduction Act of 1995, 44U.S.C.Chapter 35 and thus is based in law. Landsat, AVHRR and other broad coverage data owned or purchased by federal agencies are to be priced for users at the cost of fulfilling the user request (COFUR) and disseminating the data.

In March 1994, a Presidential Decision Directive (PDD-23) was issued that defined national objectives for remote sensing commercialization and foreign access to remote sensing space capabilities. It encouraged the U.S. remote sensing industry to pursue a significant share of the projected worldwide market for the sale of remote sensing systems and products. The policy tried to balance the U.S. commercial and national security interests by creating a tiered structure for protection of U.S. satellite technology with relatively few restrictions imposed on the sale of remote sensing data. Shortly after the PDD the Landsat Remote Sensing Strategy (NSTC-3, May 1994) was issued to provide strategies for Landsat data continuity with minimal data gaps given the failure of Landsat 6.

The Commercial Space Act of 1998 (P.L.105-303) amends some language of the Remote Sensing Policy Act of 1992 and promises that the federal government will not undertake remote sensing activities which duplicate those available from the commercial sector. In addition, the Commercial Space Act encourages the acquisition and use of commercial Earth observing data by NASA and other government agencies, though sometimes to the point of diffusing the intention of other policies. US Department of

${ }^{\dagger+\dagger}$ Failures of commercial remote sensing satellites include EOSAT / Space Imaging's Landsat-6 (10/93), and IKONOS-1 (4/99), France's SPOT-3 (11/96), Earth Watch's EarlyBird-1 (12/97), and QuickBird-1 (11/00), and ORBIMAGE's Orbview-4 (9/01). 
Agriculturc (USDA), a very large user of Landsat data, in an effort to acquire data from a commercial source whenever possible, now purchases Landsat data from a private Canadian firm. The same data, paid for and owned by the U.S. government, is available from USGS's EROS Data Center (EDC), which is not a commercial source. In this case, taxpayers are paying multiple times for Landsat data.

\section{Policy Framework}

The policy drive toward moving as many government functions into the private sector continues in 2001. The prevailing theory is that out sourcing to the private sector, functions currently performed by the government, is economically more efficient. The Department of Defense (DoD) is also supporting the commercialization of remote sensing through its recent data purchase agreements and by increasing budgets and strategic planning for commercial data use ${ }^{10}$.

Given the litany of legislation listed in the above section, at times stating conflicting policies, some have suggested that U.S. remote sensing policy is being developed on an ad hoc basis, rather than systematically and strategically ${ }^{11}$. I would suggest an alternative view, that U.S. remote sensing policy, like most U.S. policy is being developed on an evolutionary basis, no radical shifts, simply adjustments. Each amendment and iteration considers what policies exist today, what we have learned from them and what might be changed to get closer to where we would like to be. A certain path dependency dictates the evolutionary options available at any point in time. Rather than trying to determine the optimum set of policies, which is probably impossible, we iterate on what we have, optimizing from the last version.

The Landsat 7 data policy of open access and marginal cost of reproduction, with no restrictions on distribution and reproduction continues to support the international principle of non-discriminatory access and data availability to all. The Commercial Space Act has NASA purchasing data for scientific use from commercial systems if possible, yet private remote sensing firms, in order to ensure profitability, must retain the rights to their data and restrict reproduction and distribution through data licenses. This hinders scientific use of the data since sharing data and results becomes difficult. One might conclude that there is an inherent conflict between the two policies, if all remote sensing systems are the same. But they are not. The UN Remote Sensing Principles address Earth remote sensing from space, including commercial systems, but they specifically describe the data applications to which they apply in the definitions in Principles I, $X$ and XI, environmental monitoring and natural resource management. This implies the broad coverage systems described in the introduction of this paper. Landsat, AVHRR and other broad coverage systems are governed by the principle of non-discriminatory access, while limited coverage systems, mostly commercial, high-resolution systems, can choose the path of competitive advantage and profits.

Within the language of legislation and debate, there is still no distinction made between limited coverage systems (LCS), whose designs are well suited for commercialization and maximum profitability and broad coverage systems (BCS), designed for large-scale resource monitoring and global-scale studies. If policies are to support both the interests of the private sector and the public good nature of broad coverage systems, this taxonomy must be considered. The current policy framework is not sufficient without further details to support the evolving uses of remote sensing data.

\section{Economic Framework}

Barriers to market entry

In addition to high start up cost and the long time from conception to revenue stream previously mentioned, additional barriers to market entry exist in the 2001 time frame. The inherent technical risks in developing and operating satellites are high for government systems and even higher for the private sector given that private companies have limited resources and system acquisition experience compared to U.S. government programs ${ }^{12}$. The economic failure of the space telecommunications industry has generated caution among venture capitalists and financing for space ventures is difficult to acquire. The current set of public policies are favorable for private remote sensing companies, but looking on recent history, those policies are subject to change. U.S. policy stability is essential to the private sector for credibility, investment strategies and market planning. Less predictability reduces incentives to invest. New emphasis on national and homeland security has the potential to generate new restrictions for remote sensing systems. Then again, it may affect expanded remote sensing use and applications.

Competition

The proliferation of foreign national systems continues to expand and commercial systems are finding serious competition from Canada, France, Russia, India, Japan, and Israel ${ }^{13}$. The early success of SPOT 
Image, which experienced a 42 percent growth betwecn 1986 and 1991, cncouraged observers of the industry to conclude that the growth would be maintained and that it signaled a rapidly growing marketplace for commercial remote sensing satellite products and services ${ }^{14}$. Firms entered the market place, but the demand for data has not grown quite as rapidly as expected and the proliferation of foreign national systems reduces market demand even further. As a result, the competition is steep for limited coverage systems, substitute goods abound and private companies need to distinguish themselves in features and products offered.

Broad coverage systems have also increased in number, with most nations choosing to provide open access to the data for scientific and environmental studies. Competition is less critical for broad coverage systems since data sharing is the general principle and most are government funded public good systems. In theory, the more data that is available to the scientific community, the more environmental and global climate science will advance.

Aerial remote sensing systems have long been direct competitors of space remote sensing systems. Their platforms are more cost effective than space platforms, particularly if the area of coverage desired is small or localized. They have the advantage of flexibility. They can mostly fly when and where they are required, and with any revisit frequency. Aerial systems can fly advanced sensors and instruments earlier than space systems, which need a high level of technology maturity to achieve space qualification, and aerial instruments can be repaired as needed. Other the other hand, aerial remote sensing systems are very limited in the geographic area they are able to cover and airspace restrictions and flight limitations apply. They are a well established, attractive substitute for LCS satellite data and the risks from uncertainties in policy and regulations that face U.S. commercial remote sensing satellite firms, often do not apply to aerial systems. Space based commercial remote sensing systems will not replace these existing sources of remote sensing data, which is produced at reduced costs and commercial LCS will be challenged to wrest market share away from these competitors.

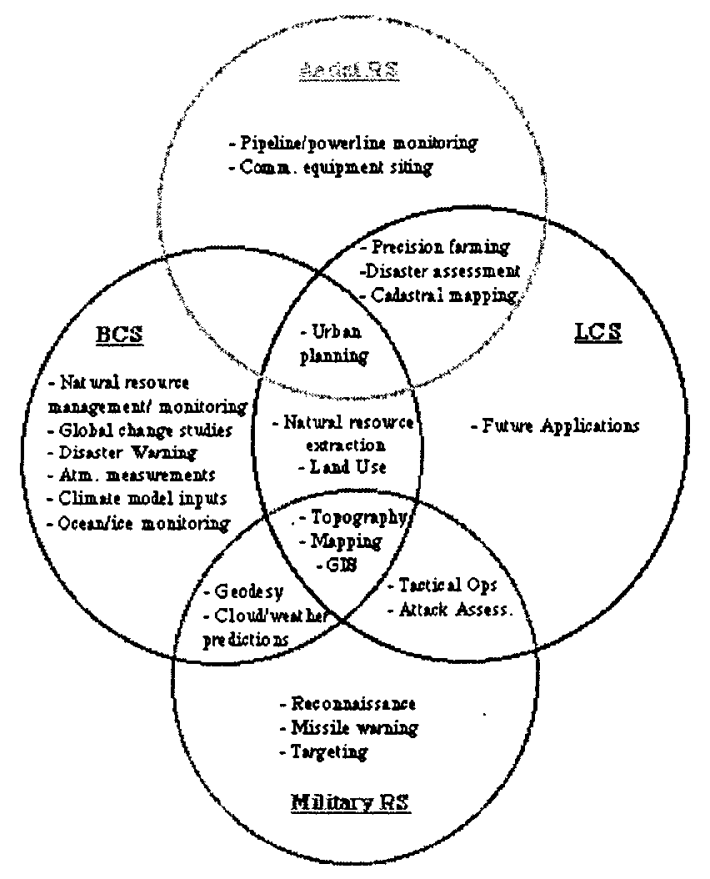

Figure 2 - User Applications by System Type

\section{Demand}

Figure 2 depicts four types of remote sensing systems and some of their current applications. The drawing is not meant to be comprehensive but intended to show where the market demand is shared and where the systems' unique characteristics generate separate markets. Aerial systems have a unique niche within the remote sensing market due to their flexibility and limited coverage, but some user applications 
could substitute space based remote sensing data for aerial data. Military remote sensing systems have unique applications, more due to the nature of their owners and users than their particular technical characteristics. But as described earlier, there is a policy trend toward more use of commercial remote sensing data to satisfy the needs of military users. Here, there is a great potential for market share for the LCS. BCS have many applications and users, some of which can be captured by the LCS market. But they also have a unique set of applications that cannot be substituted by LCS. Were LCS to capture the market for all their applications, there would still be a need for BCS, since the BCS data supply could not be provided by the other types of systems. The demand for data from BCS is not the same as that for LCS. They are not the same market. Inferring the behavior and growth of one market from the other is a flawed method of generating and extrapolating a demand curve.

This separation of markets is evidenced by the fact that the commercial market for satellite remote sensing has been slow to develop, even though the aerial remote sensing market has been growing steadily ${ }^{15}$. The growth in Landsat users has not translated into a growth of IKONOS users. There has been an increase in the number of new users of Landsat data, due to the Landsat 7 data policy and pricing. More than half of the orders received at EDC for Landsat 7 data are new users ordering 1-2 scenes each. Depending on their application needs, these users may or may not be able to substitute IKONOS data for Landsat data. Some current Landsat users can shift to commercial LCS coverage to meet their needs, but others, managing large scale natural resources or performing global climate change research, cannot.

Neither does increased demand for LCS translate into demand for broad coverage systems such as Landsat. They constitute separate markets. Users of high-resolution LCS include NIMA for national security use, precision agriculture, the extraction industries, local governments for resource planning and those currently using aerial imagery. While the users of BCS that have global acquisition strategies include the global change research community and federal government (e.g. USDA, NASA, and NOAA).

The rise of other geospatial technologies, such as GPS and GIS are better gauges of the potential growth in the market for LCS data since they are complementary products rather than substitutes. GIS and GPS are enabling technologies that can lead the market for remote sensing data. As GIS applications grow and are integrated into mainstream businesses, the need for remote sensing data to feed those applications will increase. Currently, there is not a pent up demand for LCS data, except perhaps from the national security community. The demand will be generated through new products, services and applications that add value, i.e. data that is better, quicker, cheaper, or more reliable. Substitute goods are possible on each of these different margins and will have to be assessed to determine whether they matter enough to customers for them to pay a premium for them.

Table 2 - Summary Conditions for Landsat Commercialization

\begin{tabular}{|c|c|c|}
\hline & 1984 & 2001 \\
\hline $\begin{array}{l}\text { State of } \\
\text { Technology }\end{array}$ & $\begin{array}{l}\text { - Best spatial resolution } 30 \mathrm{~m} \text { with } 185 \mathrm{~km} \text { swath } \\
\text { - Use of data relay satellite system } \\
\text { - International ground station network } \\
\text { - Broad coverage weather and ocean viewing } \\
\text { - On-board tape recorder data storage }\end{array}$ & $\begin{array}{l}\text { - Best spatial resolution } .62 \mathrm{~m} \text { with } 16 \mathrm{~km} \text { swath } \\
\text { - Stereoscopic imaging } \\
\text { - Digital terrain models } \\
\text { - GPS accuracy for S/C and ground control ties } \\
\text { - GIS applications and technology } \\
\text { - High communications bandwidth } \\
\text { - On-board solid-state data storage } \\
\text { - Loss-less data compression } \\
\text { - Proliferation of SAR systems } \\
\text { - Proliferation of ocean color systems } \\
\text { - Multiple launch failures of commercial remote } \\
\text { sensing satellites }\end{array}$ \\
\hline $\begin{array}{l}\text { Legal } \\
\text { Framework }\end{array}$ & $\begin{array}{l}\text { - UN Outer Space Treaty, } 1967 \\
\text { - Land RS Commercialization Act, } 1984 \\
\text { - UN Remote Sensing Principles, drafts }\end{array}$ & $\begin{array}{l}\text { - UN Remote Sensing Principles, } 1987 \\
\text { - Land Remote Sensing Policy Act, } 1992 \\
\text { - First commercial license issued, } 1993 \\
\text { - Presidential Decision Directive-23 - } 1994 \\
\text { - Landsat Remote Sensing Strategy - } 1994 \\
\text { - OMB Circular A-130, } 1996 \\
\text { - National Space Policy - } 1996 \\
\text { - Commercial Space Act, } 1998 \\
\text { - NOAA(revised) Licensing Regulations, } 2000 \\
\end{array}$ \\
\hline
\end{tabular}




\begin{tabular}{|c|c|c|}
\hline $\begin{array}{l}\text { Policy } \\
\text { Framework }\end{array}$ & $\begin{array}{l}\text { - Trend toward privatization } \\
\text { - Expansion of NOAA responsibility } \\
\text { - Organizational uncertainty for NOAA } \\
\text { - Divergent policies for land remote sensing and } \\
\text { weather satellites. }\end{array}$ & $\begin{array}{l}\text { - Continued trend toward privatization } \\
\text { - Increase in DoD use of commercial data sources } \\
\text { - Commercial RS licenses granted by NOAA (17) } \\
\text { - Evolutionary policy changes } \\
\text { - No distinction made between BCS and LCS }\end{array}$ \\
\hline $\begin{array}{l}\text { Economic } \\
\text { Conditions }\end{array}$ & - Significant barriers to market entry & $\begin{array}{l}\text { - Still significant barriers to market entry } \\
\text { - Venture capital difficult to get } \\
\text { - Existence of purely commercial RS satellites }\end{array}$ \\
\hline $\begin{array}{l}\text { Competition } \\
\text { (supply) }\end{array}$ & - US monopoly on land remote sensing & $\begin{array}{l}\text { - Commercial U.S. remote sensing systems } \\
\text { - International remote sensing systems } \\
\text { - Digital aerial systems } \\
\text { - Landsat } 7\end{array}$ \\
\hline Demand & $\begin{array}{l}\text { - Few data points for assessment } \\
\text { - Projections for high growth } \\
\text { - Marginal data pricing of Landsat }\end{array}$ & $\begin{array}{l}\text { - Initial optimistic growth projections in } 1990^{\prime} \text { 's } \\
\text { - More conservative projections in } 2001 \\
\text { - After } 16 \text { years of market data pricing, Landsat } \\
\text { priced at COFUR again } \\
\text { - Separate markets exist for BCS and LCS with } \\
\text { limited overlap }\end{array}$ \\
\hline
\end{tabular}

\section{CONCLUSIONS}

In the U.S., continuously acquired global monitoring data represent a national asset for understanding human activities and their resulting global environmental changes. Data from BCS are used by and essential for government agencies such as USDA, Environmental Protection Agency (EPA), Department of Interior (DOI), and NASA. One can argue by analogy with weather satellite data, that since the government needs to collect this data for its use anyway, the marginal cost of sharing it with the public is minimal. This is true for the U.S. publicly funded systems. It is in the national interest and general public good to ensure that data are collected, archived and disseminated on an open and non-discriminatory basis. But more and more, the pressure to privatize is drawing decision makers away from this public good argument toward that of commercial market viability. LCS are well suited for commercialization. Their data are acquired for those willing to pay and since LCS have limited resources (imaging capacity), they generate rival goods for a commercial market place. Assuming market growth that allows plenty for everyone, more competition could mean better quality and lower costs for users. But as we have seen, the remote sensing market is not a single market. Different types of data applications generate a different set of users and therefore demand for broad and limited coverage systems. The economic conditions for BCS and LCS are not equivalent and it would be inaccurate to draw conclusions about the commercial success of a BCS like Landsat from those of LCS such as the U.S. commercial high-resolution systems.

Large time scale changes to the environment can only be detected with systematic, long-term archives of synoptic global data that provide consistent, comparable Earth remote sensing data over time. Measurements must be periodic in order to capture cyclical and unique natural phenomena. Given the fast paced advances in commercial, high-resolution systems and sensors, it will be difficult today and in the near future to find a multi-temporal data set of any area of the world spanning more than 5 years. Changing spectral bands and sensor characteristics for improvements to maximize profits and customer base will inhibit the collection of a consistent set of multi-temporal data that can be used for global change research or time comparison studies.

To the question of whether conditions have changed sufficiently to suggest commercial success for Landsat, policies today are certainly more conducive to commercialization, but the market demand has not changed for BCS. Under today's market conditions, a purely commercial Landsat cannot yet be selfsustaining, let alone profit making, without active government subsidies, whether in the form of guaranteed data purchases or up front cost sharing. Until there is a sufficient market beyond government users, commercial BCS will be dependent on governments to sustain them. Even though there has been an increase in government applications and use of Landsat data, particularly at the federal level, one must be careful about translating this increase of use to an increase of demand. Landsat data have a great deal of public good characteristics and what has not yet been determined, is the willingness of each government agency to pay for such data. Current DoD and NASA budgets include increased spending for commercial remote sensing data, but other government agencies have not yet followed suit. Are agencies willing to budget for the cost of purchasing Landsat data at market prices? Are taxpayers willing to pay for the same 
data multiple times or is there a way to avoid this potential waste of budgetary resources? Aggregating federal agencies' needs and willingness to pay will go a long way toward determining whether a Landsat continuity mission can be a viable commercial venture.

In an attempt to keep up with changes in technology and on the world stage, the U.S. has developed a set of some times conflicting policies, implemented within multiple agencies. It is time for the next evolutionary change in our policies, one that recognizes the distinction between broad coverage and limited coverage remote sensing systems and their separate markets. Including this taxonomy within remote sensing policies is essential to support both the objectives of commercial firms and the public sector.

\section{REFERENCES}

${ }^{1}$ Space Applications Board (SAB), National Research Council, Remote Sensing of the Earth from Space: A Program in Crisis, 1985

${ }^{2}$ UN Outer Space Treaty (1967). Treaty on Principles Governing the Activities of States in the Exploration and Use of Outer Space, Including the Moon and Other Celestial Bodies, 27 January 1967, 610 U.N.T.S. 205, 18 U.S.T. 2410, TIAS No .6347, 6 I.L.M. 386

${ }^{3}$ UN Remote Sensing Principles (1987). United Nations Principles Relating to Remote Sensing of the Earth from Space, GA Res. 41/65 (XLI), UN GAOR, 29 Sess, 95 ${ }^{\text {th }}$ Plen. Mtg., UN Doc A/RES/41/65 (1987).

${ }^{4}$ Gabrynowicz,J.I., personal telephone interview, Oct.7, 2002 and Gabrynowicz; J.I., The Promise and Problems of the Land Remote Sensing Policy Act of 1992', Space Policy, Nov. 1993, p319

${ }^{5}$ Office of Technology Assessment, Congress of the United States, Remote Sensing and the Private Sector, OTA-TM-ISC-20, 1984

${ }^{6}$ McLucas, John L., Space Commerce, Harvard University Press, 1991 and Williamson, R.A., 'Remote Sensing Policy and the Development of Commercial Remote Sensing', within Baker, J., O'Connell, $\mathrm{K}$ and Williamson, R. (eds.), Commercial Observation Satellites - At the Leading Edge of Global Transparency, RAND and ASPRS publication, 2001

${ }^{7}$ Gabrynowicz, J.I., The Promise and Problems of the Land Remote Sensing Policy Act of 1992', Space Policy, Nov. 1993, p319 and O'Connell,K.M., and Hilgenberg, G, U.S. Remote Sensing Programs and Policies, and Williamson, R.A., 'Remote Sensing Policy and the Development of Commercial Remote Sensing', both within Baker, J., O'Connell, $\mathrm{K}$ and Williamson, R. (eds.), Commercial Observation Satellites - At the Leading Edge of Global Transparency, RAND and ASPRS publication, 2001 and Office of Technology Assessment, Congress of the United States, Civilian Satellite Remote Sensing: a Strategic Approach, OTA-ISS-607, Sept. 1994 to identify only a few such analyses.

${ }^{8}$ Baker, J.C. and Johnson, D.J., Security Implications of Commercial Satellite Imagery, within Baker, J., O'Connell, $\mathrm{K}$ and Williamson, R. (eds.), Commercial Observation Satellites - At the Leading Edge of Global Transparency, RAND and ASPRS publication, 2001

${ }^{9}$ Gabrynowicz, J. I., Defining Data Availability for Commercial Remote Sensing Systems Under United States Federal Law, 23 Annals of Air and Space Law 93, at 94 (1998)

${ }^{10}$ National Imagery and Mapping Agency (NIMA), Commercial Imagery Business Plan, May 2002 and Bates, J., Pentagon to Increase Spending on Satellite Imagery, Space News, 24 June 2002 are just two references among many.

${ }^{11}$ O'Connell, K.M. and Lachman, B.E., From Space imagery to Information: Commercial Remote Sensing Market Factors and Trends, within Baker, J., O'Connell, $\mathrm{K}$ and Williamson, R. (eds.), Commercial Observation Satellites - At the Leading Edge of Global Transparency, RAND and ASPRS publication,2001

${ }^{12}$ O’Connell, K.M., Baker, J.C., Lachman, B.E., Berner, S., Frelinger, D., Gavin, K., U.S. Commercial Remote Sensing Satellite Industry: An Analysis of Risks, RAND, 2001

${ }^{13}$ Glackin, D.L., Peltzer, G.R.,Civil. Commercial, and International Remote Sensing Systems and Geoprocessing The Aerospace Press, 1999

${ }^{14}$ O' Connell and Lachman

${ }^{15}$ O'Connell, Baker, Lachman, Berner, Frelinger, and Gavin 